\title{
Design of Optimal Maintenance Policy using Markov Model
}

\author{
Velmurugan K, Venkumar P, Sudhakarapandian R
}

\begin{abstract}
The availability of the machine is the major consideration of all manufacturing industries. This activity leads to decide productivity of the industry. This research paper explained in detail about the availability analysis of the Timing Belt (V-Belt) manufacturing systems in the rubber industry. The performance of the belt manufacturing systems is analyzed by using the Markovian Birth-Death approach in all conditions of the systems like Raw, Reduced capacity and Repair (RRR). The transition diagram of the belt manufacturing process is drawn by the actual layout of the belt manufacturing process in the rubber industry and then developed the first-order differential and steady-state mathematical equation of the belt manufacturing process in the rubber industry. This approach is most widely used for sequence operation problems and this is the suitable mathematical model for the performance analysis of systems because this model predicts the future sequence of the model with respect to the current sequence model of the process industry. This approach can easily denote the repairable systems of all conditions (RRR). The main goal of this research analysis is to identify the effective subsystem of the belt manufacturing process in the rubber industry by the graphical representation of the changes in the availability and variations of the failure, repair rate of the subsystem of the best manufacturing process in the rubber industry. The variety of the failure rate and repair rate of the systems and the decision matrix of the subsystems is developed by the Markovian Birth-Death approach. The mathematical equations of all subsystems are solved by using MATLAB programming.
\end{abstract}

Keywords: Availability, Raw Reduced capacity Repair (RRR), Markovian Birth Death Approach.

\section{INTRODUCTION}

$\mathrm{N}$ ow a days the availability of the system is most significant function of all the manufacturing industry due to the competitive working environment so the Reliability Availability Maintainability (RAM) analysis [9] plays a the role in the recent world. The most effective and optimal reliability, availability of the subsystem is main consideration for achieve the maximum productivity of the given manufacturing industry. The availability analysis is the most important function to the better decision making activity of the maintenance management organization. In this research analysis we are use the belt manufacturing process of the

Revised Manuscript Received on July 22, 2019.

* Correspondence Author

Velmurugan K, Research Scholar, Department of Mechanical Engineering, Kalasalingam Academy of Research and Education, Krishnankoil, Tamil Nadu, India. velmurugan@klu.ac.in

Venkumar P*, Professor, Department of Mechanical Engineering, Kalasalingam Academy of Research and Education, Krishnankoil, Tamil Nadu, India. p.venkumar@klu.ac.in

Sudhakarapandian R, Professor, Department of Manufacturing Engineering, Vellore Institute of Technology, Vellore, Tamil Nadu, India. sudhame@gmail.com rubber industry. The rubber industry have more number of complex operation to produce the final product to the customer this operation of subsystems are arranged in series order. Generally all the process industries consist the more number of systems and subsystems if anyone failed or repaired total production will affect because all the subsystems are depended on previous machine input due to sequence manufacturing operation. In this research analysis we particularly discussed in plant two manufacturing process these plants consist of the four major subsystems (A, B, C, D) are arranged in series operation of the manufacturing system where $\mathrm{A}=$ Calendaring, $\mathrm{B}=\mathrm{Bias}$ Cutting, $\mathrm{C}=\mathrm{Building}$ and $\mathrm{D}=$ Vulcanizing. The flow process of the belt manufacturing is detailed explained in the next section in that condition we analyze the three stages (Raw, Reduced capacity, Repair) of all the subsystems in belt manufacturing industry.

\section{A. System Description}

The Timing Belt (V- Belt) manufacturing system having three major working plants there are explained in below Plant 1: This is a simple and primary process plant of the belt manufacturing industry. It is consist of four subsystems like (Raw Material, Rubber Mixing, Cracker and Feeder Milling) these all subsystems are arranged in series working process Plant 2: This is the nowadays working plant of the rubber industry. It consists of the four major subsystems in this research study we choose this plant for maintenance analysis that systems are detailed explained in below

Subsystem A: The calendaring is first operation of the plant 2 manufacturing process. In this process the mixed rubber is feed into the three roller for reduce the required thickness (3-5mm) of the input rubber mixing.

Subsystem B: The Bias Cutting is next operation of the plant 2. In this process the rubber sheet is cut into required length by using the rotating cutting blade in moving conveyor.

Subsystem C: The Building is another operation of the plant 2. In this process two or more number of the required length rubber sheet is arranged in one over to other for making the green belt material.

Subsystem D: The Vulcanizing or curing process is next operation of the plant 2 . In this the green belt material is vulcanized by apply the high pressure and temperature steam at given time (3-5 min).

Plant 3: This plant having the final operations of belt manufacturing process this plant consist of the five subsystems like (Cooling, Stripping, Sleeve Cutting, Profile Grinding, Inspection and Packaging).

These all subsystems are arranged in sequence operation of the belt manufacturing process of the rubber industry. 
The flow process of the belt manufacturing in rubber industry is shown in Fig. 1.This research paper consists of the five sections. The present section is introductory type with systems descriptions.

The second section presents the various literature survey related to this research including problem statement and Markov model whereas third section is concerned with mathematical analysis of the belt manufacturing system including the Nomenclature, Assumptions and Formulation of the systems. In fourth section presents the result and analysis of the system. Finally the fifth and end section dealt with the conclusion of the research paper.

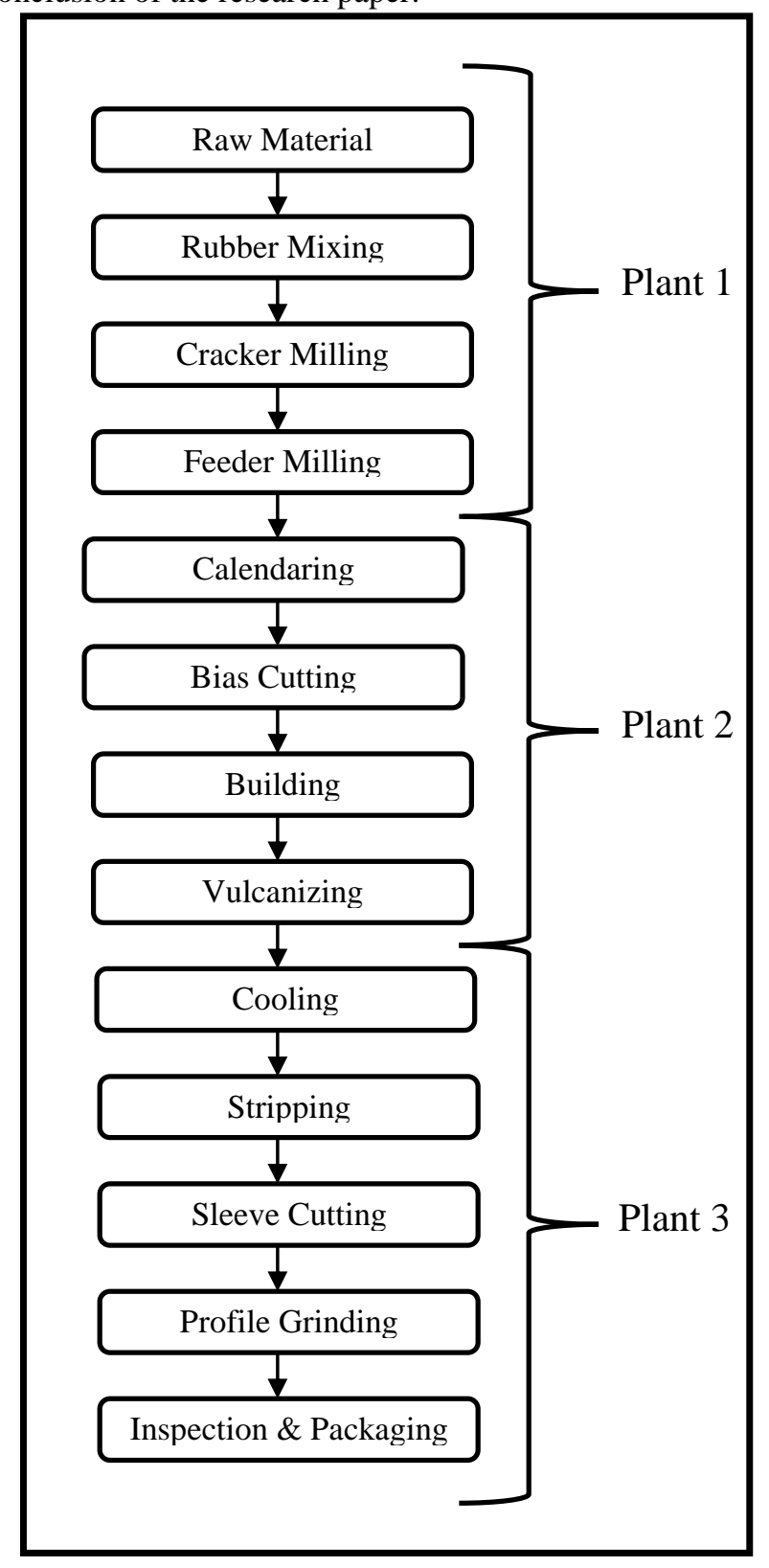

Fig. 1 Belt manufacturing Flow Process

\section{LITERATURE REVIEW}

Ajay Kumar et al. [1] explained about the performance modelling and analysis of the Malt Mill System in brewery plant. From this research paper they are analysed the availability function subsystem of the Malt Mill System in brewery plant and identified the critical subsystem of the brewery plant by using the Markov model ,Range Kutta method and Chapman-Kolmogorov differential equations for develop the mathematical equation by the transition diagram of the given Malt Mill system. The mathematical equations and decision matrix of failure rate, repair rate variations are measured by using the MATLAB programming tool. Sorabh Gupta [2] detailed discussed about the performance analysis of the water condensate system of the coal-based thermal power plant in northern India. According to this research they are analysed one of the subsystem (water condensate system) in the thermal power plant and suggest the suitable technique for stochastic modelling and availability evaluation of the given sub system of the thermal power plant by using the traditional Markov model approach and Chapman Kolmogorov equations are developed by the transition diagram of the water condensate system in thermal power plant. P.C. Tewari and Subhash Malik [3] According to this research study they are explained in detailed about the literature survey of the Reliability Availability Maintainability (RAM) and Economic Analysis of the coal fired thermal power plant to increase the productivity and availability of the subsystem in coal fired thermal power plant by using Traditional Markov Birth Death Process. A.K. Aggarwal et al. [4] explained about the performance modelling and availability analysis of the Urea Synthesis System in fertilizer production plant. From the research and analysis studies they are produced to the suitable maintenance techniques for increase the performance of the subsystem availability in the fertilizer production plant by using the Transition Diagram of the Urea Synthesis system, Markov model, First order Chapman - Kolmogorov differential equations and these equations are solved by the Range Kutta fourth order method. Attila Csenki [5] detailed discussed about the performance analysis of the various filed like Power Transmission line, Small computer working system by the application of the Markov Chain process with discrete and continuous time factors. From this research they are produced the better availability of the given working environment. Sunil Kadiyan et al. [6] discussed about the Uncaser system in brewery plant availability, reliability and performance analysis of the sub system in brewery plant of beer manufacturing process. From this research studies they analyse the sub systems of brewery plant and predict the most critical sub system with respect to the availability changes. The Transition Diagram is drawn from the actual Uncaser system in brewery plant and then develop the mathematical equation of the subsystem by using Markov Birth Death process. The variation of the failure rate, repair rate and decision matrices are generated as well as all the mathematical equations are solved by the application of the MATLAB programming. R.Khanduja et al. [7] detailed discussed about the Reliability Availability Maintainability analysis of the Digesting system of paper plant industry. From this research paper they are analyzed the performance of all subsystem of Digesting system in paper plant and produced the optimized maintenance policy of the given working manufacturing industry by using the Markov Model process to develop the mathematical equations of differential equation from the transition diagram of actual flow process of paper plant. The Genetic Algorithm Technique used for produced the optimized maintenance policy and better performance modelling of the Digesting system in paper plant. 
S.Kaushick and I.P.Singh [8] explained in detailed about the feed water system of the thermal power plant. From this research studies they are carried out the work in a sub system of the thermal power plant. They are analysed the performance and availability function of the feed water system in thermal power plant and suggest the best availability plan and guide of the given working plant by using the transition diagram of the subsystem and applied the Transforms of differential difference equation, Laplace Transform technique for solve the mathematical equation of the subsystem in thermal power plant. Komal et.al [9] discussed in detail about the manufacturing process of the papermaking industry. From this research, they are select the major two sub system of paper making industry like Pressing and Washing system. They are analysed Reliability Availability Maintainability (RAM) of the both subsystems of the paper making industry and provide the best idea for improve the performance and RAM of the subsystem in paper making industry. For this purpose they are using the Genetic Algorithm based Lambda Tau (GABLT) technique to solve this problems in paper making industry. D.D.Adhikary et al. [10] explained about the case study of the all the subsystem of the $210 \mathrm{MW}$ coal fired thermal power plant in eastern region of India. From this research studies they analyse the Reliability Availability Maintainability (RAM) function of all the subsystems in coal fired thermal power plant and suggest the best decision making and planning of the Preventive Maintenance activity to the thermal power plant. For this purpose they are used Pareto Analysis to identified the significance of the subsystems in coal fired thermal power plant and applied the Wei bull distribution functions for develop the mathematical equations of the given working plant as well as used the some Goodness of Fit test like subsystem Test and Kolmogorove - Smirov Test for select the suitable maintenance policy of the coal fired thermal power plant in eastern region India. D.V.Rajee et al. [11] discussed in detail about the pumping system of oil refinery industry. According to this research they are understand the pumping system and analysis the availability function of the subsystems in the refinery industry then they produced the best availability Simulation model of the pumping systems in refinery industry by using the Markovian approach of the two stage pumping system in oil refinery industry. Raiiv Kumar Sharma and Sunand Kumar [12] explained about the subsystems like ammonia production system and urea production system in fertilizer production plant in northern region India. From this research paper they are produced the best maintenance technique for improve the effectiveness and Reliability, Availability of the subsystems in fertilizer production plant. For this purpose they are drawn the transition diagram from the actual manufacturing process fertilizer production plant and using Markov Model for developing mathematical model to achieve the effective reliability analysis of the fertilizer production plant. Javad Barabady [13] discussed about the Reliability Availability Maintainability (RAM) analysis of the crushing plant in Iran. From this research paper they are understand the process of the subsystems in crushing plant then suggest the better maintenance techniques to achieve the effective RAM analysis to the working plant. For this purpose they are using the Non Homogeneous Poisson Process (NHPP) and some mathematical analysis software like ReliaSoft's Wei bull ++6 software in the analysis of the subsystems of crushing plant in Iran.

\section{A. Problem statement}

The decision making of the maintenance management activity is the major problems in all the manufacturing industry. In this research analysis we choose the Timing Belt (V - Belt) manufacturing process of rubber industry in southern region of Tamil Nadu, India. We are better understanding the flow process of the belt manufacturing system by the direct visit of the industry and discussed with employees in rubber industry. The belt manufacturing systems having the number of working subsystems that are connected in series operation so all subsystems depend upon the previous system inputs. The maximum productivity of the industry depends on the better availability of the subsystems in the rubber industry. The poor availability and reliability of the subsystems directly affect the total profit of the manufacturing industry. The analysis of the Reliability Availability Maintainability (RAM) of the system is the most important consideration of all the manufacturing industry.

Initially we are monitor the existing manufacturing and maintenance activity of the belt manufacturing systems in detailed then discussed with the plant employee for addressing the maintenance requirement and problems in given working plant. After that we are collect the present data of the maintenance activity of the subsystems in given manufacturing plant for the further investigation of this research studies.

\section{B. Markov Model}

The Markov Model is best tool for RAM analysis of the all the systems because this approach is redundancy management methods of sequence operation problem solving. It predicting the future sequence of the model with respect to analyse the current behaviour of the variables. This model is also called as the Markovian Birth-Death approach and it is invented by the Russian mathematician A.A.Markov for solved the sequence problems. The reliability and availability of the systems are can easily predict the more industrial system by the application the Reliability Block Diagram (RBD) but this is not easy because it have only two state operating function so the industrial systems are using more number of reliability prediction tools such as Markov Birth Death approach, Fault Tree Analysis (FTA), Petri nets and semi Markov process. The Markov analysis is best tool for predicting the repairable system of the given working environment. Here we use the Markov Analysis is like a decision analysis of the repairable system. This analysis is not a optimization techniques it is probabilistic technique $t$ produced the probabilistic information about the better decision making of the Maintenance Management System (MMS).This Markov analysis can be classified in two types there are

1. Discrete Markov Analysis (Markov Model)

2. Continuous Markov Analysis (Markov Chain)

\section{Analysis AND Mathematical Model}

In this section concerned in detail about the analysis and the mathematical modelling of the belt manufacturing systems in rubber industry. 
The belt manufacturing process of all the subsystem are analysed then applied the Markov Birth Death approach for predict the availability of the repairable systems in rubber industry. The better understanding of the actual layout of the belt manufacturing process as shown in Fig.1.After that we generate the Transition Diagram (TD) by the actual the belt manufacturing process with three stages like Raw, Reduces capacity, Repair (RRR) of the systems. The transition diagrams are successfully drawn with two conditions. There are given below

1. The TD was drawn all individual systems are under repairable condition of the given sequence of the manufacturing process in rubber industry.

2. The TD was drawn for simultaneously both systems are under repairable condition of the given sequence of the manufacturing process in rubber industry.

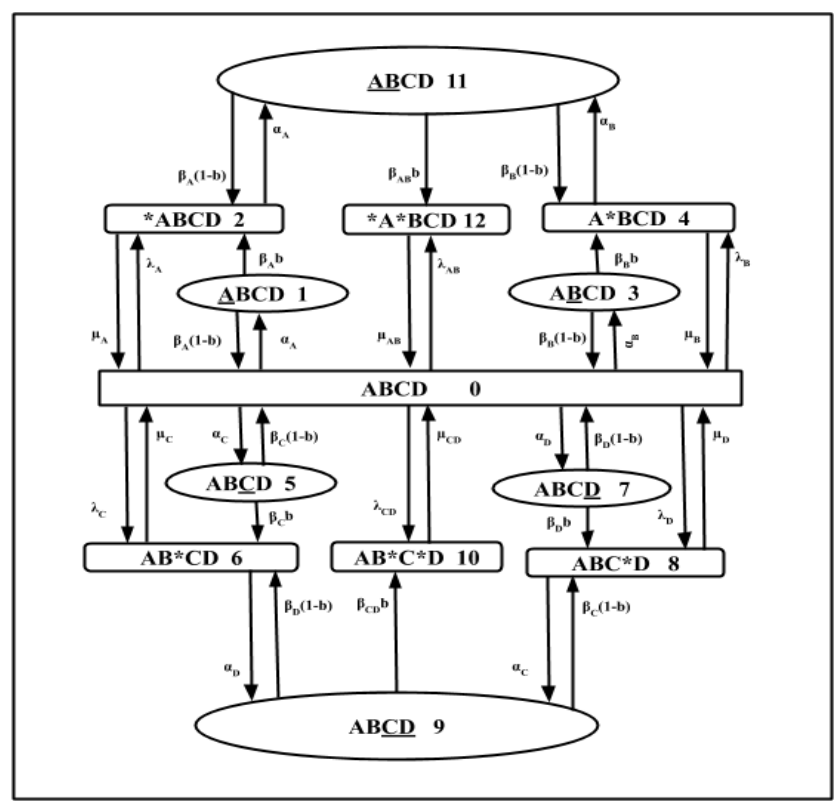

Fig.2 Transition Diagram of belt manufacturing system

The Transition Diagram of the belt manufacturing process in rubber industry is shown in Fig.2.From the TD we develop the mathematical modelling and equations of the given manufacturing systems in rubber industry. We generate first order differential difference equation from the Transition Diagram and the Markov Birth Death approach to identify the availability of the subsystems in belt manufacturing process of rubber industry.

\section{A. Nomenclature}

A, B, C, D Represent the full working state or Raw of the subsystems

$\underline{\mathrm{A}}, \underline{\mathrm{B}}, \underline{\mathrm{C}}, \underline{\mathrm{D}}$ Represent the under maintenance or Reduced Capacity of the subsystems.

$* \mathrm{~A}, * \mathrm{~B},{ }^{*} \mathrm{C}, * \mathrm{D}$ Represent the failure state or Repair state of the subsystems

PM Represent the Preventive Maintenance

$\lambda_{A}$ Represent the failure rate of subsystem A

$\lambda_{B}$ Represent the failure rate of subsystem B

$\lambda_{C}$ Represent the failure rate of subsystem $\mathrm{C}$

$\lambda_{D}$ Represent the failure rate of subsystem D

$\lambda_{C D}$ Represent the failure rate of subsystems CD
$\lambda_{A B}$ Represent the failure rate of subsystems AB

$\mu_{A}$ Represent the repair rate of subsystem A

$\mu_{B}$ Represent the repair rate of subsystem B

$\mu_{C}$ Represent the repair rate of subsystem C

$\mu_{D}$ Represent the repair rate of subsystem D

$\mu_{C D}$ Represent the repair rate of subsystems CD

$\mu_{A B}$ Represent the repair rate of subsystems AB

$\alpha_{A}$ Represent the transition rate of Subsystem A

$\alpha_{B}$ Represent the transition rate of subsystem B

$\alpha_{C}$ Represent the transition rate of subsystem C

$\alpha_{D}$ Represent the transition rate of subsystem D

$\alpha_{C D}$ Represent the transition rate of subsystems CD

$\alpha_{A B}$ Represent the transition rate of Subsystem AB

$\beta_{A}$ Represent the PM rate of subsystem A

$\beta_{B}$ Represent the PM rate of subsystem $\mathrm{B}$

$\beta_{C}$ Represent the PM rate of subsystem C

$\beta_{D}$ Represent the PM rate of subsystem D

$\beta_{C D}$ Represent the PM rate of subsystems CD

$\beta_{A B}$ Represent the PM rate of subsystems AB

$b$ Represent the constant value of the subsystems,

$\mathrm{P}_{0}(\mathrm{t})$ refer the probability function of all subsystems are in Raw / original state.

$\mathrm{P}_{1}(\mathrm{t})$ refer the probability function of subsystem $\mathrm{A}$ is Reduced capacity / under maintenance state.

$\mathrm{P}_{2}(\mathrm{t})$ refer the probability function of subsystem $\mathrm{A}$ is under the Repair state.

$\mathrm{P}_{3}(\mathrm{t})$ refer the probability function of subsystem $\mathrm{B}$ is Reduced capacity / under maintenance state.

$\mathrm{P}_{4}(\mathrm{t})$ refer the probability function of subsystem $\mathrm{B}$ is under the Repair state.

$\mathrm{P}_{5}(\mathrm{t})$ refer the probability function of subsystem $\mathrm{C}$ is Reduced capacity / under maintenance state.

$\mathrm{P}_{6}(\mathrm{t})$ refer the probability function of subsystem $\mathrm{C}$ is under the Repair state.

$\mathrm{P}_{7}(\mathrm{t})$ refer the probability function of subsystem $\mathrm{D}$ is Reduced capacity / under maintenance state.

$\mathrm{P}_{8}(\mathrm{t})$ refer the probability function of critical subsystem $\mathrm{D}$ is under the Repair state.

$\mathrm{P}_{9}(\mathrm{t})$ refer the probability function of subsystems $\mathrm{CD}$ is Reduced capacity / under maintenance state.

$\mathrm{P}_{10}(\mathrm{t})$ refer the probability function of subsystems $\mathrm{CD}$ is under the Repair state.

$\mathrm{P}_{11}(\mathrm{t})$ refer the probability function of subsystems $A B$ is Reduced capacity / under maintenance state.

$\mathrm{P}_{12}(\mathrm{t})$ refer the probability function of subsystems $A B$ is under the Repair state.

\section{B. Assumptions}

The various assumptions are considered in this proposed mathematical model of the given subsystems of the belt manufacturing process are as follows:- 
I. All the subsystems are initially operate in original/Raw state.

II. Every subsystems are have three states viz. Raw, Reduced capacity and Repair (RRR). Repair.

III. Every subsystems are assumed as original/Raw after

IV. Failure and repair events of the subsystems are statistically independent.

$\mathrm{V}$. The rate of failure of the all subsystems are considered as constant,

VI. The rate of repair of the all subsystems are considered as constant,

VII. The rate of preventive maintenance of all the Subsystems are consider as constant.

\section{Formulation of the belt manufacturing System}

From the transition diagram of the belt manufacturing system of rubber industry we identified the maximum Reliability and Availability of belt manufacturing system in rubber industry by the theoretical formulation of the given manufacturing systems are solved by applying the first order differential difference equations. Finally we generate the Markov Birth Death approach of all the subsystems in belt manufacturing system with three stages like RRR.

The probability function of the subsystem A is start the transform from the raw/original state to reduced capacity state of mathematical equation is given below

$$
\beta_{A} P_{1}(t)=\alpha_{A} P_{0}(t)
$$

The probability function of the subsystem A is start transform from the reduced capacity state to repair state then finally get back to the Raw/original state of mathematical equation is given below

$$
\mu_{A} P_{2}(t)=\beta_{A} b P_{1}(t)+\lambda_{A} P_{0}(t)
$$

The probability function of the subsystem B is start transform from the Raw/original state to reduced capacity state of mathematical equation is given below

$$
\beta_{B} P_{3}(t)=\alpha_{B} P_{0}(t)
$$

The probability function of the subsystem B is start transform from the reduced capacity state to Repair state then finally get back to the raw/ original state of mathematical equation is given below

$$
\mu_{B} P_{4}(t)=\beta_{B} b P_{3}(t)+\lambda_{B} P_{0}(t)
$$

The probability function of the subsystem $\mathrm{C}$ is start transform from the raw/ original state to reduced capacity state of mathematical equation is given below

$$
\beta_{C} P_{5}(t)=\alpha_{C} P_{0}(t)
$$

The probability function of the subsystem $\mathrm{C}$ is start transform from the reduced capacity state to repair state then finally get back to the raw/original state of mathematical equation is given below

$$
\mu_{C} P_{6}(t)=\beta_{C} b P_{5}(t)+\lambda_{C} P_{0}(t)
$$

The probability function of the subsystem D is start transform from the raw/original state to reduced capacity state of mathematical equation is given below

$$
\beta_{D} P_{7}(t)=\alpha_{D} P_{0}(t)
$$

The probability function of the subsystem D is start transform from the reduced capacity state to repair state then finally get back to the raw/original state of mathematical equation is given below

$$
\mu_{D} P_{8}(t)=\beta_{D} b P_{7}(t)+\lambda_{D} P_{0}(t)
$$

The probability function of the subsystems C and D are start transform from the raw/original state to reduced capacity state of mathematical equation is given below

$$
\beta_{C D} P_{9}(t)=\alpha_{C} P_{8}(t)+\alpha_{D} P_{6}(t)
$$

The probability function of the subsystems C and D are start transform from the reduced capacity state to repair state then finally get back to the raw/original state of mathematical equation is given below

$$
\mu_{C D} P_{10}(t)=\beta_{C D} b P_{9}(t)+\lambda_{C D} P_{0}(t)
$$

The probability function of the subsystems A and B are start transform from the raw/original state to reduced capacity state of mathematical equation is given below

$$
\beta_{A B} P_{11}(t)=\alpha_{A} P_{4}(t)+\alpha_{B} P_{2}(t)
$$

The probability function of the subsystem A and B are start transform from the reduced capacity state to repair state then final get back to the raw/original state of mathematical equation is given below

$\mu_{A B} P_{12}(t)=\beta_{A B} b P_{11}(t)+\lambda_{A B} P_{0}(t)$

The belt manufacturing process of all the subsystems are assumed to be a steady state condition. In this conditions the time changes of all the subsystems are assumed to be a zero that mean $\mathrm{t}=0$. The steady state condition is applied the above equations 1-12 finally we get the steady state probability equations of the belt manufacturing subsystems. $\beta_{A} P_{1}=\alpha_{A} P_{0}$

$\mu_{A} P_{2}=\beta_{A} b P_{1}+\lambda_{A} P_{0}$

$\beta_{B} P_{3}=\alpha_{B} P_{0}$

$\mu_{B} P_{4}=\beta_{B} b P_{3}+\lambda_{B} P_{0}$

$\beta_{C} P_{5}=\alpha_{C} P_{0}$

$\mu_{C} P_{6}=\beta_{C} b P_{5}+\lambda_{C} P_{0}$

$\beta_{D} P_{7}=\alpha_{D} P_{0}$

$\mu_{D} P_{8}=\beta_{D} b P_{7}+\lambda_{D} P_{0}$

$\beta_{C D} P_{9}=\alpha_{C} P_{8}+\alpha_{D} P_{6}$

$\mu_{C D} P_{10}=\beta_{C D} b P_{9}+\lambda_{C D} P_{0}$

$\beta_{A B} P_{11}=\alpha_{A} P_{4}+\alpha_{B} P_{2}$ 
$\mu_{A B} P_{12}=\beta_{A B} b P_{11}+\lambda_{A B} P_{0}$

$P=\frac{\alpha_{A}}{\beta_{A}} P_{0}+\frac{\alpha_{A} b+\lambda_{A}}{\mu_{A}} P_{0}+\frac{\alpha_{B}}{\beta_{B}} P_{0}+\frac{\alpha_{B} b+\lambda_{B}}{\mu_{B}} P_{0}+$

$\frac{\alpha_{C}}{\beta_{C}} P_{0}+\frac{\alpha_{C} b+\lambda_{C}}{\mu_{C}} P_{0}+\frac{\alpha_{D}}{\beta_{D}} P_{0}+\frac{\alpha_{D} b+\lambda_{D}}{\mu_{D}} P_{0}+$

$\frac{3 \alpha_{C D}+\lambda_{C D}}{\beta_{C D}} P_{0}+\frac{3 \alpha_{C D}+2 \lambda_{C D}}{\mu_{C D}} P_{0}+\frac{3 \alpha_{A B}+2 \lambda_{A B}}{\beta_{A B}} P_{0}+$

$\frac{3 \alpha_{A B}+2 \lambda_{A B}}{\mu_{A B}} P_{0}$

$P=\left(\begin{array}{l}P_{1}+P_{2}+P_{3}+P_{4}+P_{5}+P_{6}+ \\ P_{7}+P_{8}+P_{9}+P_{10}+P_{11}+P_{12}\end{array}\right) P_{0}$

The steady state probability function of the belt manufacturing subsystems are identified then apply the normalizing condition. The summation of all the probability functions in belt manufacturing system is equal to 1 the normalizing condition equation is given below

Using Normalizing condition

$$
\begin{aligned}
& \sum_{i=1}^{12} P_{i}=1 \\
& P_{0}=\left(1+\sum_{i=1}^{12} P_{i}\right)^{-1} \\
& A_{0}=P_{0}
\end{aligned}
$$

Availability of the system $=0.7397($ Faulty $b=1)$

Availability of the system $=0.7901$ (Ideal $b=0)$

The Numerical values of rate of failure, repair, transition and Preventive Maintenance of the subsystems of belt manufacturing process in rubber industry are applied the final equation the numerical values of the subsystems are shown in Table I. we directly find out the availability of the subsystem in both condition like $b=0, b=1$ ( ideal, repair).

\section{Table- I: Numerical values of the Critical subsystem}

The MATLAB Programming is used for applied the various samples and also measure the corresponding availability of the subsystem as well as find out the decision matrix of the all the subsystems of belt manufacturing process in rubber industry these matrix are used for the better decision making activity of the maintenance management system in rubber industry. The decision matrix of all the subsystems and changes of availability with respect to the failure, repair rate vales are detailed explained in graphical representation.

\section{RESUlt AND ANALYSIS}

In Timing belt manufacturing process of all the subsystems in rubber industry are successfully carried out the availability analysis with the help of the Markovian Birth-Death approach and MATLAB programming. From this research analysis we identified the availability changes of the individual subsystem
24) and as well as simultaneously series of two subsystems are in repairable condition. We measure the availability and reliability of the subsystems with respect to the variation of failure and repair rate of the corresponding subsystems of belt manufacturing process in rubber industry. The availability of the belt manufacturing system is 0.7397 under faulty condition $(b=1)$ and the ideal condition $(b=0)$ availability of the system is 0.7901 . Also we develop the decision matrix of all subsystems for the better decision making of the maintenance management systems in belt manufacturing system of rubber industry. The decision matrix and the availability changes of all the subsystems are detailed explain in graphical representation. These graph will produce the clear explanation of the most effective subsystem of belt manufacturing process in rubber industry. Generally the availability of all the subsystems of belt manufacturing process are gradually decrease and increase with depends up on the corresponding maintenance properties of the subsystems like (rate of Failure and Repair)

The decision matrix and availability variations are depends on rate of failure of the subsystem A (Calendaring system) is graphically represented and as shown in Fig.3. The Table II shows the decision matrix values of the system A. The availability of the system A is gradually decrease with depends on the corresponding rate of failure $(0.006-0.012)$ of the system A.

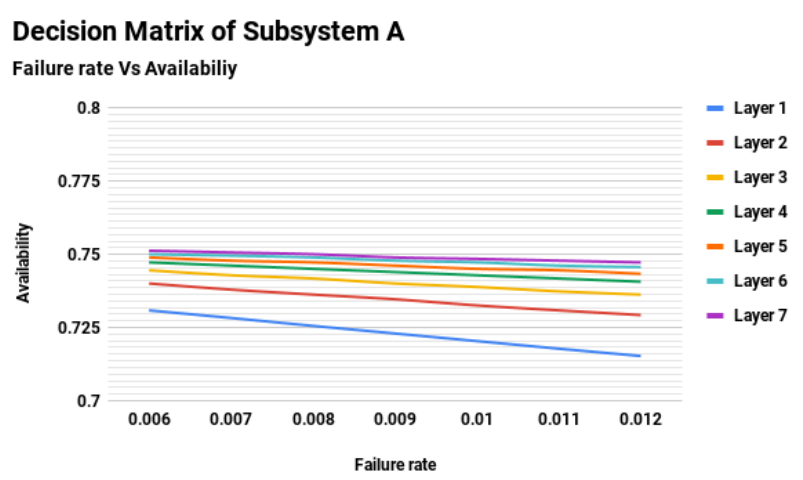

Fig.3 Failure rate and Availability of subsystem A

The decision matrix and availability variations are depends on rate of repair of the subsystem A (Calendaring system) is graphically represented and as shown in Fig.4. The

\begin{tabular}{|l|l|l|l|l|l|l|l|}
\hline \multicolumn{2}{|c|}{$\begin{array}{l}\text { Failure Rate } \\
\lambda\end{array}$} & \multicolumn{2}{l|}{$\begin{array}{l}\text { Repair } \\
\text { Rate } \mu\end{array}$} & \multicolumn{2}{l|}{$\begin{array}{l}\text { Transition } \\
\text { Rate } \alpha_{1}\end{array}$} & \multicolumn{2}{l|}{$\begin{array}{l}\text { Preventive } \\
\text { Maintenance } \\
\text { Rate } \beta\end{array}$} \\
\hline$\lambda_{\mathrm{A}}$ & 0.009 & $\mu_{\mathrm{A}}$ & 0.50 & $\alpha_{\mathrm{A}}$ & 0.004 & $\beta_{\mathrm{A}}$ & 0.55 \\
\hline$\lambda_{\mathrm{B}}$ & 0.008 & $\mu_{\mathrm{B}}$ & 0.43 & $\alpha_{\mathrm{B}}$ & 0.006 & $\beta_{\mathrm{B}}$ & 0.43 \\
\hline$\lambda_{\mathrm{C}}$ & 0.009 & $\mu_{\mathrm{C}}$ & 0.55 & $\alpha_{\mathrm{C}}$ & 0.004 & $\beta_{\mathrm{C}}$ & 0.55 \\
\hline$\lambda_{\mathrm{D}}$ & 0.010 & $\mu_{\mathrm{D}}$ & 0.52 & $\alpha_{\mathrm{D}}$ & 0.005 & $\beta_{\mathrm{D}}$ & 0.52 \\
\hline$\lambda_{\mathrm{CD}}$ & 0.009 & $\mu_{\mathrm{C}}$ & 0.53 & $\alpha_{\mathrm{CD}}$ & 0.004 & $\beta_{\mathrm{CD}}$ & 0.53 \\
\hline$\lambda_{\mathrm{AB}}$ & 0.008 & $\mu_{\mathrm{AB}}$ & 0.46 & $\alpha_{\mathrm{AB}}$ & 0.005 & $\beta_{\mathrm{AB}}$ & 0.49 \\
\hline
\end{tabular}

availability of the system $A$ is gradually increase with depends on the corresponding rate of repair $(0.2-0.8)$ of the system A. 


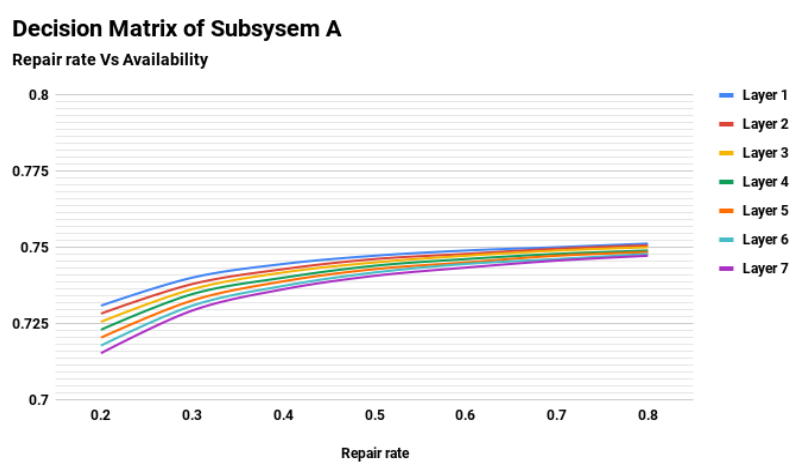

Fig.4 Repair rate and Availability of subsystem A

The decision matrix and availability variations depends on rate of failure of the subsystem B (Bias Cutting system) is graphically represented and as shown in Fig.5. The Table III shows the decision matrix values of the system B. The availability of the system B is gradually decrease with depends on the corresponding rate of failure $(0.005-0.011)$ of the system B.

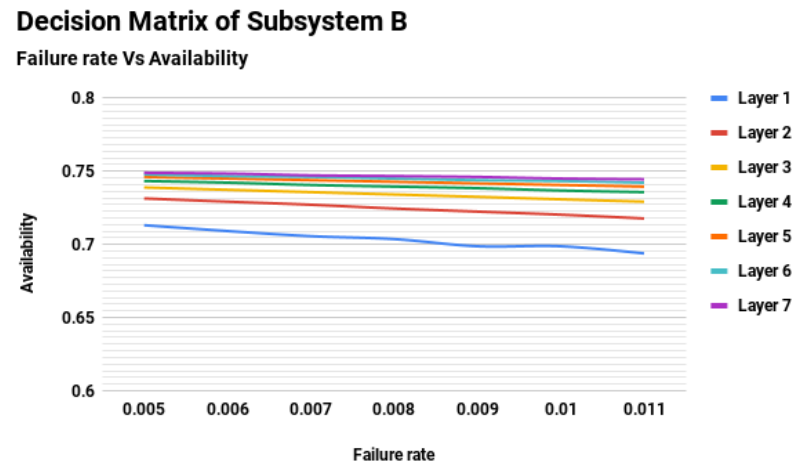

Fig.5 Failure rate and Availability of subsystem B

The decision matrix and availability variations depends on rate of repair of the subsystem B (Bias Cutting system) is graphically represented and as shown in Fig.6. The availability of the system $B$ is gradually increase with depends on the corresponding rate of repair $(0.13-0.73)$ of the system B.

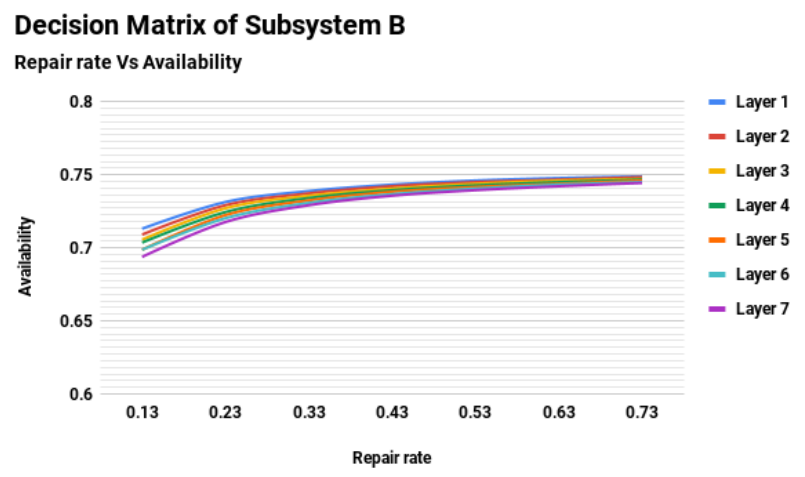

Fig.6 Repair rate and Availability of subsystem B

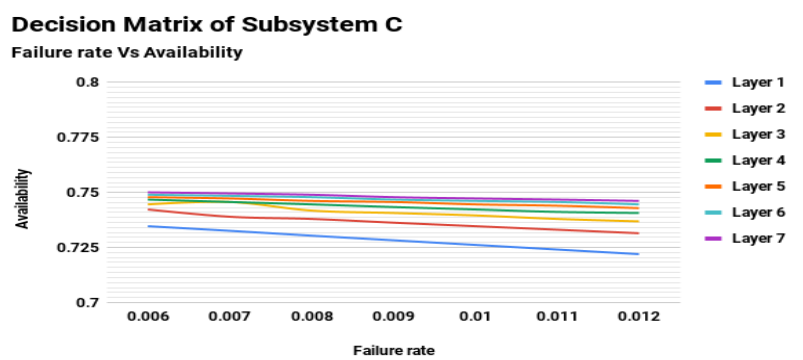

Fig.7 Failure rate and Availability of subsystem C

The decision matrix and availability variations are depends on rate of failure of the subsystem $\mathrm{C}$ (Building system) is graphically represented and as shown in Fig.7. The Table IV shows the decision matrix values of the system $\mathrm{C}$ The availability of the system $C$ is abruptly changed with depends on the corresponding rate of failure $(0.006-0.012)$ of the system $\mathrm{C}$.

The decision matrix and availability variations are depends on rate of repair of the subsystem $\mathrm{C}$ (Building system) is graphically represented and as shown in Fig.8. The availability of the system $\mathrm{C}$ is abruptly changed with depends on the corresponding rate of repair $(0.25-0.85)$ of the system C.

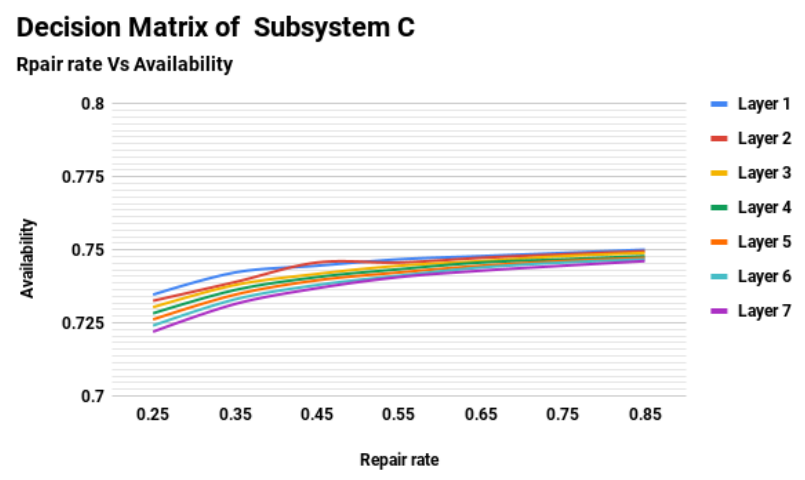

Fig.8 Repair rate and Availability of subsystem C

The decision matrix and availability variations are depends on rate of failure of the subsystem D (Vulcanizing system) is graphically represented and as shown in Fig.9. The Table V shows the decision matrix values of the system $D$. The availability of the system $\mathrm{D}$ is abruptly changed with depends on the corresponding rate of failure $(0.007-0.013)$ of the system D

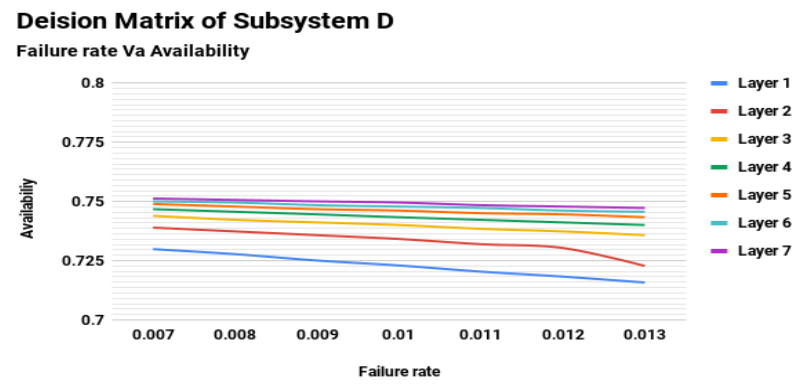

Fig.9 Failure rate and Availability of subsystem D 


\section{Reliability Availability Maintainability Analysis in Forming Industry}

The decision matrix and availability variations are depends on rate of repair of the subsystem D (Vulcanizing system) is graphically represented shown in Fig.10. The availability of the system $\mathrm{D}$ is abruptly changed with depends on the corresponding rate of repair $(0.22-0.82)$ of the system D.

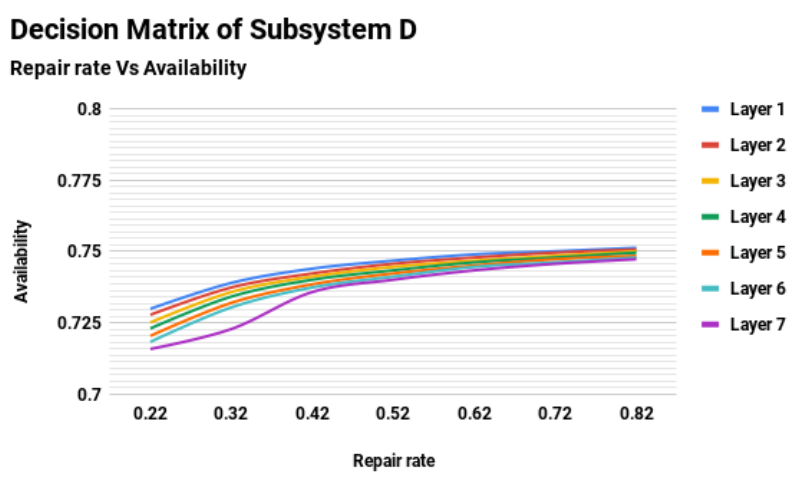

Fig.10 Repair rate and Availability of subsystem D

The decision matrix and availability variations are depends on rate of failure of the subsystems CD (Building, Vulcanizing system) are graphically represented and as shown in Fig.11. The Table VI shows the decision matrix values of the system $\mathrm{CD}$. The availability of the system $\mathrm{CD}$ is gradually changed with depends on the corresponding rate of failure $(0.006-0.012)$ of the system CD

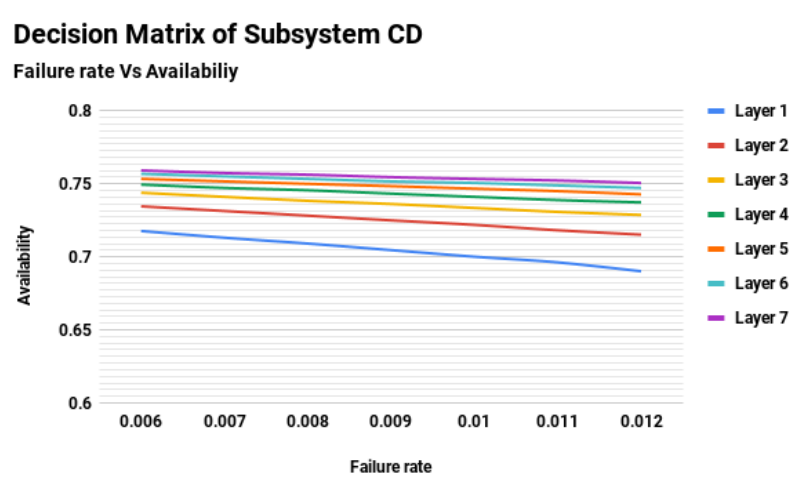

Fig.11 Failure rate and Availability of subsystems CD

The decision matrix and availability variations are depends on rate of repair of the subsystems CD (Building, Vulcanizing system) is graphically represented and as shown in Fig.12. The availability of the system CD is gradually increase with depends on the corresponding rate of repair $(0.23-0.83)$ of the system CD.

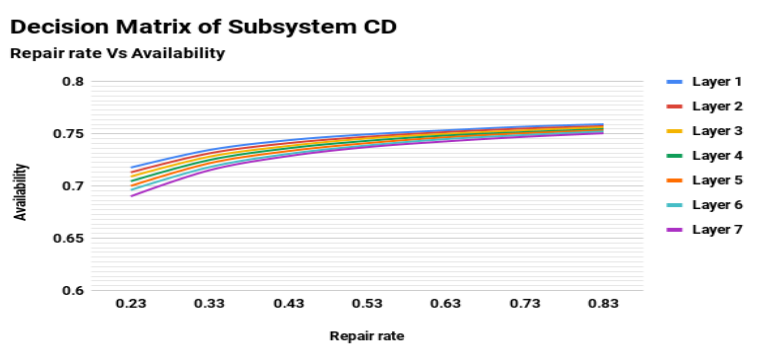

Fig.12 Repair rate and Availability of subsystems CD

Table-II: Decision Matrix of subsystem A $\left(\lambda_{\mathrm{A}}, \mu_{\mathrm{A}}\right)$

\begin{tabular}{|c|c|c|c|c|c|c|c|c|c|}
\hline$\frac{\lambda_{A}}{\mu_{A}}$ & 0.006 & 0.007 & 0.008 & 0.009 & 0.01 & 0.011 & 0.012 & \multicolumn{2}{|c|}{$\begin{array}{c}\text { Constant } \\
\text { Values }\end{array}$} \\
\hline 0.2 & 0.7309 & 0.7283 & 0.7256 & 0.723 & 0.7204 & 0.7178 & 0.7153 & $\begin{array}{l}\lambda_{\mathrm{B}}=0.008, \\
\lambda_{\mathrm{C}}=0.009, \\
\lambda_{\mathrm{D}}=0.01, \\
\lambda_{\mathrm{CD}}=0.009, \\
\lambda_{\mathrm{AB}}=0.008,\end{array}$ & $\begin{array}{l}\mu_{\mathrm{B}}=0.43 \\
\mu_{\mathrm{C}}=\mathbf{0 . 5 5} \\
\mu_{\mathrm{D}}=\mathbf{0 . 5 2} \\
\mu_{\mathrm{CD}}=\mathbf{0 . 5 3} \\
\mu_{\mathrm{AB}}=\mathbf{0 . 4 6}\end{array}$ \\
\hline 0.3 & 0.7401 & 0.738 & 0.7363 & 0.7347 & 0.7326 & 0.7309 & 0.7293 & $\alpha_{A}=0.004$ & $\beta_{\mathrm{A}}=0.55$ \\
\hline 0.4 & 0.7446 & 0.7429 & 0.7418 & 0.7401 & 0.7389 & 0.7374 & 0.7363 & $\alpha_{\mathrm{B}}=0.006$ & $\beta_{B}=0.43$ \\
\hline 0.5 & 0.7473 & 0.7462 & 0.7451 & 0.744 & 0.7429 & 0.7418 & 0.7407 & $\alpha_{C}=0.004$ & $\beta_{C}=0.55$ \\
\hline 0.6 & 0.749 & 0,7479 & 0.7473 & 0.7462 & 0.7451 & 0.7446 & 0.7434 & $\alpha_{D}=0.005$ & $\beta_{D}=0.52$ \\
\hline 0.7 & 0.7501 & 0.7496 & 0.749 & 0.7479 & 0.7473 & 0.7462 & 0.7457 & $\alpha_{\mathrm{CD}}=0.005$, & $\beta_{\mathrm{CD}}=0.49$ \\
\hline 0.8 & 0.7513 & 0.7507 & 0.7501 & 0.749 & 0.7485 & 0.7479 & 0.7473 & $\alpha_{\mathrm{AB}}=0.004$ & $\beta_{\mathrm{AB}}=0.53$ \\
\hline
\end{tabular}


International Journal of Engineering and Advanced Technology (IJEAT) ISSN: 2249 - 8958, Volume-9 Issue-1S4, December 2019

Table-III: Decision Matrix of subsystem B $\left(\lambda_{B}, \mu_{B}\right)$

\begin{tabular}{|c|c|c|c|c|c|c|c|c|}
\hline$\frac{\lambda_{\mathrm{B}}}{\mu_{\mathrm{B}}}$ & 0.005 & 0.006 & 0.007 & 0.008 & 0.009 & 0.01 & 0.011 & $\begin{array}{c}\text { Constant } \\
\text { Values }\end{array}$ \\
\hline 0.13 & 0.7132 & 0.7092 & 0.7057 & 0.7037 & 0.6988 & 0.6988 & 0.6939 & \multirow{7}{*}{$\begin{array}{rr}\lambda_{\mathrm{A}}=\mathbf{0 . 0 0 9}, & \boldsymbol{\mu}_{\mathrm{A}}=\mathbf{0 . 5 0} \\
\lambda_{\mathrm{C}}=\mathbf{0 . 0 0 9}, & \boldsymbol{\mu}_{\mathrm{C}}=\mathbf{0 . 5 5} \\
\lambda_{\mathrm{D}}=\mathbf{0 . 0 1}, & \boldsymbol{\mu}_{\mathrm{D}}=\mathbf{0 . 5 2} \\
\lambda_{\mathrm{CD}}=\mathbf{0 . 0 0 9}, & \boldsymbol{\mu}_{\mathrm{CD}}=\mathbf{0 . 5 3} \\
\lambda_{\mathrm{AB}}=\mathbf{0 . 0 0 8}, & \boldsymbol{\mu}_{\mathrm{AB}}=\mathbf{0 . 4 6} \\
& \\
\alpha_{\mathrm{A}}=\mathbf{0 . 0 0 4}, & \boldsymbol{\beta}_{\mathrm{A}}=\mathbf{0 . 5 5} \\
\alpha_{\mathrm{B}}=\mathbf{0 . 0 0 6}, & \boldsymbol{\beta}_{\mathrm{B}}=\mathbf{0 . 4 3} \\
\alpha_{\mathrm{C}}=\mathbf{0 . 0 0 4}, & \beta_{\mathrm{C}}=\mathbf{0 . 5 5} \\
\alpha_{\mathrm{D}}=\mathbf{0 . 0 0 5}, & \beta_{\mathrm{D}}=\mathbf{0 . 5 2} \\
\alpha_{\mathrm{CD}}=\mathbf{0 . 0 0 5}, & \beta_{\mathrm{CD}}=\mathbf{0 . 4 9} \\
\alpha_{\mathrm{AB}}=\mathbf{0 . 0 0 4}, & \beta_{\mathrm{AB}}=\mathbf{0 . 5 3}\end{array}$} \\
\hline 0.23 & 0.7315 & 0.7293 & 0.7272 & 0.7246 & 0.7225 & 0.7204 & 0.7178 & \\
\hline 0.33 & 0.7390 & 0.7374 & 0.7358 & 0.7342 & 0.7326 & 0.7309 & 0.7293 & \\
\hline 043 & 0.7434 & 0.7423 & 0.7407 & 0.7396 & 0.7385 & 0.7369 & 0.7358 & \\
\hline 0.53 & 0.7462 & 0.7451 & 0.7440 & 0.7429 & 0.7418 & 0.7407 & 0.7396 & \\
\hline 0.63 & 0.7479 & 0.7468 & 0.7462 & 0.7451 & 0.7440 & 0.7434 & 0.7423 & \\
\hline 0.73 & 0.7490 & 0.7485 & 0.7473 & 0.7468 & 0.7462 & 0.7451 & 0.7446 & \\
\hline
\end{tabular}

Table -IV: Decision Matrix of subsystem C $\left(\lambda_{C}, \mu_{C}\right)$

\begin{tabular}{|c|c|c|c|c|c|c|c|c|}
\hline$\frac{\lambda_{\mathrm{C}}}{\mu_{\mathrm{C}}}$ & 0.006 & 0.007 & 0.008 & 0.009 & 0.01 & 0.011 & 0.012 & $\begin{array}{c}\text { Constant } \\
\text { Values }\end{array}$ \\
\hline 0.25 & 0.7347 & 0.7326 & 0.7304 & 0.7283 & 0.7262 & 0.7241 & 0.7220 & \multirow{7}{*}{ 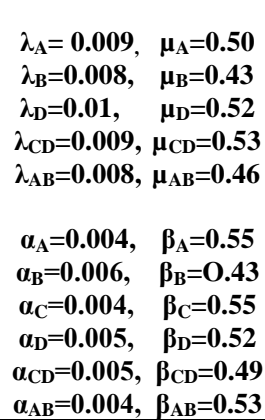 } \\
\hline 0.35 & 0.7423 & 0.7390 & 0.7380 & 0.7363 & 0.7347 & 0.7331 & 0.7315 & \\
\hline 0.45 & 0.7446 & 0.7457 & 0.7418 & 0.7407 & 0.7396 & 0.7380 & 0.7369 & \\
\hline 0.55 & 0.7468 & 0.7457 & 0.7446 & 0.7434 & 0.7423 & 0.7412 & 0.7407 & \\
\hline 0.65 & 0.7479 & 0.7473 & 0.7462 & 0.7457 & 0.7446 & 0.7440 & 0.7429 & \\
\hline 0.75 & 0.7490 & 0.7485 & 0.7479 & 0.7468 & 0.7462 & 0.7457 & 0.7446 & \\
\hline 0.85 & 0.7501 & 0.7496 & 0.7490 & 0.7479 & 0.7473 & 0.7468 & 0.7462 & \\
\hline
\end{tabular}

Table -V: Decision Matrix of subsystem D $\left(\lambda_{D}, \mu_{D}\right)$

\begin{tabular}{|c|c|c|c|c|c|c|c|c|}
\hline$\frac{\lambda_{D}}{\mu_{D}}$ & 0.007 & 0.008 & 0.009 & 0.01 & 0.011 & 0.012 & 0.013 & $\begin{array}{c}\text { Constant } \\
\text { Values }\end{array}$ \\
\hline 0.22 & 0.7299 & 0.7278 & 0.7251 & 0.7230 & 0.7204 & 0.7183 & 0.7158 & \multirow{7}{*}{$\begin{array}{ll}\lambda_{A}=0.009, & \mu_{A}=0.50 \\
\lambda_{C}=0.009, & \mu_{C}=0.55 \\
\lambda_{B}=0.008, & \mu_{D}=0.43 \\
\lambda_{C D}=0.009, & \mu_{C D}=0.53 \\
\lambda_{A B}=0.008, & \mu_{A B}=0.46 \\
\alpha_{A}=0.004, & \beta_{A}=0.55 \\
\alpha_{B}=0.006, & \beta_{B}=0.43 \\
\alpha_{C}=0.004, & \beta_{C}=0.55 \\
\alpha_{D}=0.005, & \beta_{D}=0.52 \\
\alpha_{C D}=0.005, & \beta_{C D}=0.49 \\
\alpha_{A B}=0.004, & \beta_{A B}=0.53\end{array}$} \\
\hline 0.32 & 0.7390 & 0.7374 & 0.7358 & 0.7342 & 0.7320 & 0.7304 & 0.7228 & \\
\hline 0.42 & 0.7440 & 0.7423 & 0.7412 & 0.7401 & 0.7385 & 0.7374 & 0.7358 & \\
\hline 0.52 & 0.7468 & 0.7457 & 0.7446 & 0.7434 & 0.7423 & 0.7412 & 0.7401 & \\
\hline 0.62 & 0.7490 & 0.7479 & 0.7468 & 0.7462 & 0.7451 & 0.7446 & 0.7434 & \\
\hline 0.72 & 0.7501 & 0.7496 & 0.7485 & 0.7479 & 0.7473 & 0.7462 & 0.7457 & \\
\hline 0.82 & 0.7513 & 0.7507 & 0.7501 & 0.7496 & 0.7485 & 0.7479 & 0.7473 & \\
\hline
\end{tabular}


Reliability Availability Maintainability Analysis in Forming Industry

Table-VI: Decision Matrix of subsystem CD $\left(\lambda_{\mathrm{CD}}, \mu_{\mathrm{CD}}\right)$

\begin{tabular}{|c|c|c|c|c|c|c|c|c|}
\hline$\frac{\lambda_{C D}}{\mu_{C D}}$ & 0.006 & 0.007 & 0.008 & 0.009 & 0.01 & 0.011 & 0.012 & $\begin{array}{c}\text { Constant } \\
\text { Values }\end{array}$ \\
\hline 0.23 & 0.7178 & 0.7132 & 0.7092 & 0.7047 & 0.7002 & 0.6963 & 0.6902 & $\lambda_{A}=0.009, \quad \mu_{A}=0.50$ \\
\hline 0.33 & 0.7347 & 0.7315 & 0.7283 & 0.7251 & 0.7220 & 0.7183 & 0.7153 & $\lambda_{C}=0.009, \quad \mu_{C}=0.55$ \\
\hline 0.43 & 0.7440 & 0.7412 & 0.7385 & 0.7363 & 0.7336 & 0.7309 & 0.7288 & 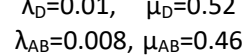 \\
\hline 0.53 & 0.7496 & 0.7473 & 0.7457 & 0.7434 & 0.7412 & 0.7390 & 0.7374 & $\alpha_{A}=0.004, \quad \beta_{A}=0.55$ \\
\hline 0.63 & 0.7535 & 0.7518 & 0.7501 & 0.7485 & 0.7468 & 0.7451 & 0.7429 & $\alpha_{B}=0.006, \quad \beta_{B}=0.43$ \\
\hline 0.73 & 0.7570 & 0.7552 & 0.7535 & 0.7518 & 0.7507 & 0.7490 & 0.7473 & $\alpha_{D}=0.005, \quad \beta_{D}=0.52$ \\
\hline 0.83 & 0.7593 & 0.7575 & 0.7564 & 0.7547 & 0.7535 & 0.7524 & 0.7507 & $\alpha_{A B}=0.004, \beta_{A B}=0.53$ \\
\hline
\end{tabular}

Table-VII: Decision Matrix of subsystem AB $\left(\lambda_{\mathrm{AB}}, \mu_{\mathrm{AB}}\right)$

\begin{tabular}{|c|c|c|c|c|c|c|c|c|}
\hline$\lambda_{\mathrm{AB}}$ & & & & & & & & Constant \\
\hline$\mu_{A B}$ & 0.005 & 0.006 & 0.007 & 0.008 & 0.009 & 0.01 & 0.011 & Values \\
\hline & & & & & & & & $\begin{array}{c}\lambda_{A}=0.009, \\
\mu_{A}=0.50 \\
\lambda_{B}=0.008, \\
\mu_{B}=0.43 \\
\lambda_{C}=0.009, \\
\mu_{C}=0.55 \\
\lambda_{D}=0.01, \\
\mu_{D}=0.52 \\
\lambda_{C D}=0.009, \\
\mu_{C D}=0.53\end{array}$ \\
\hline 0.16 & 0.6973 & 0.6915 & 0.6854 & 0.6798 & 0.6738 & 0.6684 & 0.6626 & \\
\hline 0.26 & 0.7278 & 0.7241 & 0.7199 & 0.7158 & 0.7122 & 0.7082 & 0.7042 & $\begin{array}{c}\alpha_{A}=0.004, \\
\beta_{A}=0.55\end{array}$ \\
\hline 0.36 & 0.7423 & 0.739 & 0.7363 & 0.7331 & 0.7304 & 0.7272 & 0.7246 & $\begin{array}{c}\alpha_{B}=0.006, \\
\beta_{B}=0.43\end{array}$ \\
\hline 0.46 & 0.7507 & 0.7485 & 0.7457 & 0.7434 & 0.7412 & 0.7385 & 0.7363 & $\begin{array}{c}\alpha_{c}=0.004, \\
\beta_{c}=0.55\end{array}$ \\
\hline 0.56 & 0.7564 & 0.7541 & 0.7524 & 0.7501 & 0.7485 & 0.7462 & 0.744 & $\begin{array}{c}\alpha_{D}=0.005, \\
\beta_{D}=0.52\end{array}$ \\
\hline 0.66 & 0.7604 & 0.7587 & 0.757 & 0.7552 & 0.753 & 0.7513 & 0.7496 & $\begin{array}{c}\alpha_{C D}=0.005, \\
\beta_{C D}=0.49\end{array}$ \\
\hline 0.76 & 0.7633 & 0.7616 & 0.7598 & 0.7587 & 0.757 & 0.7552 & 0.7541 & $\begin{array}{c}\alpha_{A B}=0.004, \\
\beta_{A B}=0.53\end{array}$ \\
\hline
\end{tabular}

The decision matrix and availability variations are depend on rate of failure of the subsystems $\mathrm{AB}$ (Calendaring, Bias Cutting system) is graphically represented and as shown in Fig.13. The Table VII shows the decision matrix values of the system $\mathrm{AB}$. The availability of the system $\mathrm{AB}$ is gradually decrease with depends on the corresponding rate of failure $(0.005-0.011)$ of the system $\mathrm{AB}$

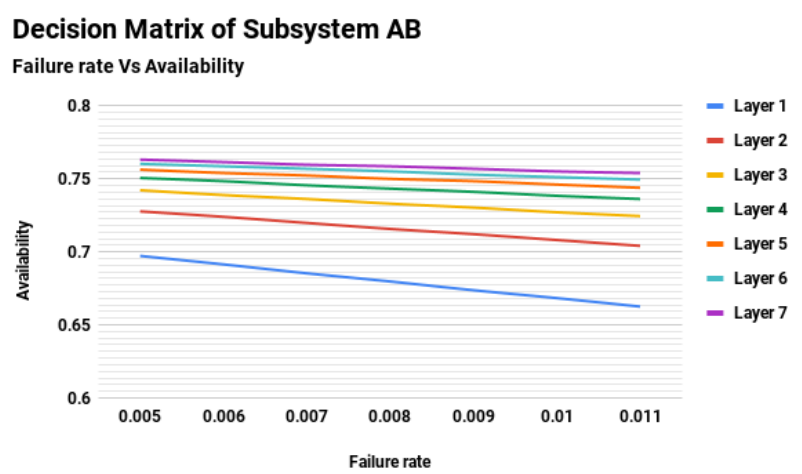

Fig.13 Failure rate and Availability of subsystems A\&B
The decision matrix and availability variations are depends on rate of repair of the subsystems $\mathrm{AB}$ (Calendaring, Bias Cutting system) is graphically represented and as shown in Fig.14. The availability of the system AB is gradually increase with depends on the corresponding rate of repair $(0.16-0.76)$ of the system AB.

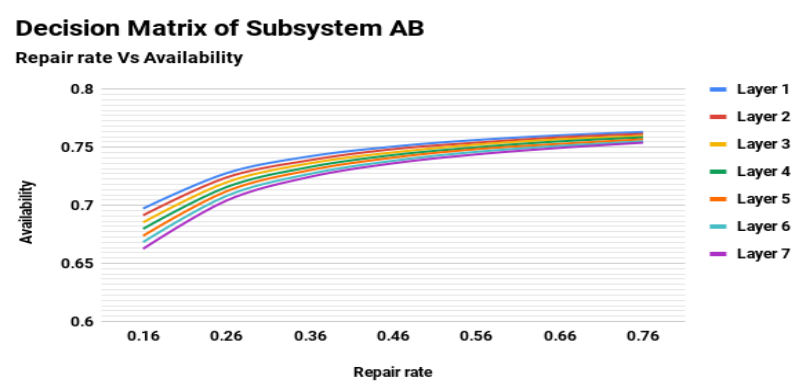

Fig.14 Repair rate and Availability of subsystems AB 


\section{CONCLuSion}

Finally, the most effective subsystem of the belt manufacturing process in the rubber industries is identified by this research analysis study. The effective subsystem of the belt manufacturing process is selected by the abrupt changes of the availability depends on the corresponding rate of failure and repair of the subsystems in the rubber industry. From this result analysis, the subsystems $\mathrm{C}$ and $\mathrm{D}$ (Building and vulcanizing system) are the most effective subsystems in the belt manufacturing process. The varied range of the rate of failure and repair of the selected subsystems is increase from 0.006 to 0.013 of the Building and Vulcanizing systems of belt manufacturing process in rubber industry. The availability value of the subsystems decrease in that case gradually increasing the range of repair rates from 0.22 to 0.85 of the Building and Vulcanizing system of the belt manufacturing process in rubber industry so the availability of the subsystems of belt manufacturing system is increasing nearly $1 \%$. In future this research analysis is also applied to any traditional or non-traditional optimization techniques for developing the better decision-making of the optimal maintenance cost of subsystems in the manufacturing industry.

\section{ACKNOWLEDGMENT}

The authors wish to thank the Management of Kalasalingam Academy of Research and Education [KARE] Krishnankoil, Tamil Nadu, India and Vellore Institute of Technology [VIT] Vellore, Tamil Nadu, India for their support in this research.

\section{REFERENCES}

1. A. Kumar, R. K. Garg, and P. C. Tiwari, "Performance Modeling and Availability Simulation of a Malt Mill System of Brewery Industry," International Journal of Current Engineering and Technology, 4(3), pp.1452-1459, 2014.

2. S. Gupta, "Stochastic modelling and availability analysis of a critical engineering system," International Journal of Quality \& Reliability Management, 36(5), pp.782-796, 2019.

3. P. C. Tewari, and S. Malik, "Simulation and economic analysis of coal based thermal power plant: a critical literature review," IOSR Journal of Mechanical and Civil Engineering (IOSR-JMCE), pp.2278-1684, 2016.

4. A. K. Aggarwal, S. Kumar, V. Singh, and T. K. Garg, "Markov modeling and reliability analysis of urea synthesis system of a fertilizer plant," Journal of Industrial Engineering International, 11(1), pp.1-14, 2015.

5. A. Csenki, "Specified demand patterns for finite Markov systems in discrete and continuous time with illustrative examples," International Journal of Reliability, Quality and Safety Engineering, 13(06), pp.547-564, 2006

6. S. Kadiyan, R. K. Garg, \& R. Gautam, "Reliability and availability analysis of uncaser system in a brewery plant," International Journal Res Mech Eng Technology, 2(2), 7-11, 2012.

7. R. Khanduja, P. C. Tewari, \& D. Kumar, "Mathematical modeling and performance optimization for the digesting system of a paper plant," International Journal of Engineering, 23(3/4), 215-225, 2010.

8. S. Kaushik, and I. P. Singh, "Reliability analysis of the feed water system in a thermal power plant," Microelectronics Reliability, 34(4), pp.757-759, 1994.

9. S. P. Sharma, and D. Kumar,"RAM analysis of repairable industrial systems utilizing uncertain data," Applied Soft Computing, 10(4), pp.1208-1221, 2010.

10. D. D. Adhikary, G. K. Bose, S. Mitra, and D. Bose, "Reliability, Maintainability \& Availability analysis of a coal fired power plant in eastern region of India," In Proceedings of the 2nd International Conference on Production and Industrial Engineering (CPIE 2010) (pp. 1505-1513), 2010.
11. D. V. Raje, R. S. Olaniya, P. D. Wakhare, and A. W. Deshpande, "Availability assessment of a two-unit stand-by pumping system," Reliability Engineering \& System Safety, 68(3), pp.269-274, 2000.

12. R. K. Sharma, and S. Kumar, "Performance modeling in critical engineering systems using RAM analysis," Reliability Engineering \& System Safety, 93(6), pp.913-919, 2008.

13. J. Barabady, "Reliability and maintainability analysis of crushing plants in Jajarm Bauxite Mine of Iran," In Annual Reliability and Maintainability Symposium, 2005. Proceedings. (pp. 109-115), 2005 IEEE.

\section{AUTHORS PROFILE}

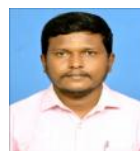

Mr. K. Velmurugan, is currently a Research Scholar, Department of the Mechanical Engineering, in Kalasalingam Academy of Research and Education, Krishnankovil, Tamil Nadu, India. He received his B.E., and M.E., degree in Anna University, Chennai, Tamil Nadu, India, in 2014 and 2017 respectively and pursuing $\mathrm{Ph} . \mathrm{D}$. degree in Kalasalingam Academy of Research and Education, Tamil Nadu, India. His main area of the research interest are Predictive Maintenance Management, Manufacturing system optimization and Smart Maintenance Management.

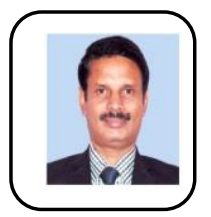

Dr. P. Venkumar, is currently a Senior Professor in Department of Mechanical Engineering, Kalasalingam Academy of Research and Education, Krishnankovil, Tamilnadu, Inida. He received his B.E., and M.E., degrees in Thigagrajar College of Engineering, Madurai, Tamilnadu, India, in 1994 and 1997, respectively and $\mathrm{Ph} . \mathrm{D}$. degree in Manonmaniam Sundaranar University, India in Industria Engineering in 2006. His main areas of research interest are Manufacturing system optimization, Supply chain management and Smart manufacturing.

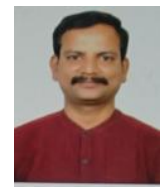

Dr. R. SudhakaraPandian, is currently a Professor in the Department of Manufacturing Engineering, School of Mechanical Engineering at Vellore Institute of Technology, Vellore, Tamil Nadu, India. He has published around 30 International papers in Journals. He is a scientific coordinator of the European Funded H2020 SME 4.0 Project along with Technical University of Kosice, Slovak Republic. He was awarded with Young Engineers Award during 2010 for his contribution in production Engineering by IE (India). His area of research include Lean Manufacturing, Mass Customization, Operations Research and Supply Chain 